\title{
Fungi in Biodegradation of Polycyclic Aromatic Hydrocarbons in Oilfield Wastewater
}

\section{Obire, 0., Aleruchi, 0.* and Wemedo, S.A}

Department of Microbiology, Rivers State University, Port Harcourt, Nigeria *Corresponding Author: Aleruchi O, Department of Microbiology, Rivers State University, Port Harcourt, Nigeria.
Received: March 12, 2020

Published: April 01, 2020

(C) All rights are reserved by Obire, $\mathbf{0 .}$,

Aleruchi, O. and Wemedo, S.A.

\section{Abstract}

Oilfield wastewater not adequately treated contains organic and inorganic substances including polycyclic aromatic hydrocarbons (PAHs). PAHs are toxic and are not easily degraded by microorganisms. Therefore, this study investigated the role of fungi in the biodegradation of PAHs in oilfield wastewater. Oilfield wastewater was collected from an onshore oil producing platform and biodegradation of polycyclic aromatic hydrocarbons was investigated using standard methods. Fungi were isolated from oilfield wastewater polluted soils obtained from the vicinity of the oil producing platform. The fungal isolates were identified molecularly using internal transcribed spacer (ITS) and identified with accession numbers as Aspergillus niger (MN094359), Aspergillus sydowii (MN094361) and Fusarium lichenicola (MN094360). Experimental control set-up and treatments contained $125 \mathrm{ml}$ of oilfield wastewater. Each of the single treatments had $12.5 \mathrm{ml}$ of mineral salt medium which contained the fungal isolates. Mixed culture treatment contained $4.17 \mathrm{ml}$ each of the fungal isolates while the control set up contained oilfield wastewater only. The experimental samples were periodically analyzed at day 7 and day 21 intervals for polycyclic aromatic hydrocarbon degradation using Gas Chromatography (GC). The total amount of PAHs in oilfield wastewater on day 1 was $101.72992 \mathrm{mg} / \mathrm{l}$. The amount of PAHs in control on day 7 and 21 was $93.01704 \mathrm{mg} / \mathrm{l}$ and $75.40663 \mathrm{mg} / \mathrm{l}$, respectively. Aspergillus niger, Aspergillus sydowii, Fusarium lichenicola and mixed culture fungi on day 21 recorded 27.0136, 27.3887, 34.7772 and $15.02925 \mathrm{mg} / \mathrm{l}$ with percentage removal of 73.4\%, 73.1\%, $65.8 \%$ and $85.2 \%$, respectively. There was a significant difference between the treatment options and the control on day 7 and 21 at $\mathrm{P} \leq 0.05$. The results therefore revealed significant reduction of PAHs in the treatment options. In addition, there was complete removal of naphthalene and chrysene by Aspergillus niger and mixed culture while Aspergillus sydowii showed removal of Chrysene only. In conclusion, fungi have great potentials in degradation of PAHs and in remediation of PAHs contaminated environments, different species of fungi have the ability to attack one or more components of PAHs and complete degradation of PAHs was best achieved by mixed fungal cultures.

Keywords: Oilfield Wastewater; PAHs; Fungi; Biodegradation; GC; Naphthalene; Chrysene

\section{Introduction}

Petroleum hydrocarbons are widely used as the most principal and versatile source of energy and it has become the most common contaminants in the environment [1]. These pollution problems results in huge disturbances of both biotic and abiotic components of the ecosystems [2]. Some of the hydrocarbon components are carcinogenic and neurotoxic organo pollutants [3]. Contamination of the environment with petroleum hydrocarbons has caused critical health issues and therefore increasing attention has been on developing and implementing innovative technology for cleaning up this contamination $[1,4]$. Contamination of environment can be caused by oil spillages, automobile workshops, gasoline petrol station and tankers during loading and offloading operations at the refinery or during clean up operations; the possible effect is that it may be ignored but continuous and prolonged spill can lead to contamination of groundwater, soil and air [1].
Polycyclic aromatic hydrocarbons are more complex and resistant to biodegradation than alkanes, although they represent less than $2 \%$ of the bulk composition of crude oil and include toxic compounds that can be of concern in the longer term (DPR, 2003). It is however important to treat oilfield wastewater before discharge into the environment to reduce their level of contamination [5].

Biodegradation is a process whereby microbes are used for breakdown of contaminants in the environment. The population of microorganisms found in a polluted environment will degrade crude oil differently and at different rate than microorganisms in a relatively clean environment [6]. Oilfield wastewater which contains organic and inorganic constituent have great potential in the biodegradation of crude oil $[7,8]$.

Fungi play an important role during biodegradation as they produce extracellular enzymes for the assimilation of complex carbohydrates. 
This study therefore investigated the biodegradation potential of fungi isolated from oilfield production vicinity.

\section{Materials and Methods}

Collection of Oilfield wastewater and soil samples

Oilfield wastewater was collected from Ogbogu Flow Station; an onshore oil production platform located in Ogba/Egbema/Ndoni local government Area (ONELGA) of Rivers State, Nigeria. The Oilfield wastewater samples were collected using 4 Litre capacity sterile sample bottles and stored in an ice packed cooler.

The soil samples were collected 80 meters away from the discharge pond at a depth of $0-15 \mathrm{~cm}$ with a clean hand auger into sterile polythene bags and stored in an ice packed cooler. The collected oilfield wastewater and soil samples were immediately transported to the laboratory for analysis within 24 hours.

\section{Soil enrichment with oilfield wastewater}

Soil enrichment with oilfield wastewater was carried out by inoculating various concentrations $(10 \%, 25 \%, 50 \%$ and $75 \%)$ of oilfield wastewater into separate $100 \mathrm{~g}$ soil samples and incubated in a rotary shaker. Samples were withdrawn at 7 days intervals during incubation for analysis.

Microbiological analysis of soils

Soil samples were analyzed microbiologically by isolation of fungal organisms. Serial tenfold dilution was carried out on each sample. Aliquot $(0.1 \mathrm{ml})$ of $10^{-2}$ dilution of each of the soil samples was spread plated onto the surface of sterile Potato dextrose agar plates to which $0.1 \mathrm{ml}$ of streptomycin solution was incorporated to suppress bacterial growth. The plates were incubated at $28^{\circ} \mathrm{C}$ for 1 - 3 days and the discrete colonies that developed were purified and molecularly identified.

\section{Identification of fungal isolates}

The fungi were identified molecularly as Aspergillus niger, Aspergillus sydowii and Fusarium lichenicola using the internal transcribed spacer. The identified isolates were submitted to the Gene Bank and were assigned accession numbers.

\section{Internal transcribed spacer (ITS) amplification of fungi}

The ITS region of the rRNA genes of the isolates was amplified using the ITS1F: 5'-CTTGGTCATTTAGAGGAAGTAA-3' and ITS4: 5'- TCCTCCGCTTATTGATATGC-3, primers on an ABI 9700 Applied Biosystems thermal cycler at a final volume of 30 microlitres for 35 cycles. The PCR mix included: the X2 Dream taq Master mix supplied by Inqaba, South Africa (taq polymerase, DNTPs, $\mathrm{MgCl}$ ), the primers at a concentration of $0.4 \mathrm{M}$ and the extracted DNA as template. The PCR conditions were as follows: Initial denaturation, 95으 $\mathrm{C}$ for 5 minutes; denaturation, $9^{\circ} \mathrm{C}$ for 30 seconds; annealing, $53^{\circ} \mathrm{C}$ for 30 seconds; extension, $72^{\circ} \mathrm{C}$ for 30 seconds for 35 cycles and final extension, $72^{\circ} \mathrm{C}$ for 5 minutes. The product was resolved on a $1 \%$ agarose gel at $120 \mathrm{~V}$ for 15 minutes and visualized on a blue light transilluminator.

\section{Sequencing}

Sequencing was done using the BigDye Terminator kit on a 3510 ABI sequencer by Inqaba Biotechnological, Pretoria, South Africa. The sequencing was done at a final volume of $10 \mathrm{ul}$, the components included 0.25 ulBigDye $^{\circledR}$ terminator v1.1/v3.1, 2.25 ul of $5 \mathrm{x}$ BigDye sequencing buffer, $10 \mathrm{uM}$ Primer PCR primer and 2 - $10 \mathrm{ng}$ PCR template per $100 \mathrm{bp}$. The sequencing condition were as follows 32 cycles of $96^{\circ} \mathrm{C}$ for $10 \mathrm{~s}, 55^{\circ} \mathrm{C}$ for 5 s and $60^{\circ} \mathrm{C}$ for 4 minutes.

\section{Phylogenetic analysis}

Obtained sequences were edited using the bioinformatics algorithm Trace edit, similar sequences were downloaded from the National Center for Biotechnology Information (NCBI) data base using BLASTN. These sequences were aligned using ClustalX. The evolutionary history was inferred using the Neighbor-Joining method in MEGA 6.0 [9]. The bootstrap consensus tree inferred from 500 replicates [10] is taken to represent the evolutionary history of the taxa analyzed. The evolutionary distances were computed using the Jukes-Cantor method [11].

\section{Biodegradation experiment}

Aspergillus niger, Aspergillus sydowii and Fusarium lichenicola isolates were subcultured onto surface of sterile potato dextrose agar plates and incubated for 3 - 5 days at ambient temperature. A portion of each fungal colonies were inoculated into $4 \mathrm{ml}$ of potato dextrose broth and incubated for 3 - 5 days at ambient temperature and thereafter transferred to $250 \mathrm{ml}$ conical flasks each containing $50 \mathrm{ml}$ of sterile defined mineral salts medium (MSM) for 3 - 5 days at ambient temperature.

The experimental set ups and control (OA1, OA2, OA3, OA4 and OA5) contained $125 \mathrm{ml}$ of oilfield wastewater each in a conical flasks. The control OA1 had the oilfield wastewater only. Flask OA2, OA3 and OA4 was inoculated with $12.5 \mathrm{ml}$ of mineral salt medium containing Aspergillus niger, Aspergillus sydowii and Fusarium lichenicola, respectively. Flask OA5 contained the mixed culture (which had $4.17 \mathrm{mg} / \mathrm{l}$ of the mineral salt medium from each of fungal isolates). The polycyclic aromatic hydrocarbons were analyzed on day 1, 7 and 21 using GC/FID.

\section{Results}

Results of the biodegradation of PAHs by single and mixed culture of fungi are shown in figure 1. The initial concentration of PAHs recorded on day 1 was $101.72992 \mathrm{mg} / \mathrm{l}$. On day 7 the control recorded $93.0171 \mathrm{mg} / \mathrm{l}$, treatments with Aspergillus niger 75.7811 
$\mathrm{mg} / \mathrm{l}$, Aspergillus sydowii $75.4065 \mathrm{mg} / \mathrm{l}$ and Fusarium lichenicola $81.4746 \mathrm{mg} / \mathrm{l}$. The mixed culture on day 7 recorded 48.30071 $\mathrm{mg} / \mathrm{l}$. On day 21, control recorded $75.4065 \mathrm{mg} / \mathrm{l}$ with percentage removal of 25.9\%, Aspergillus niger, Aspergillus sydowii and Fusarium lichenicola recorded 27.0136, 27.3887 and $34.7772 \mathrm{mg} / \mathrm{l}$, with percentage removal of $73.4 \%, 73.1 \%$ and $65.8 \%$, respectively. The mixed culture on day 21 recorded $15.02925 \mathrm{mg} / \mathrm{l}$ with $85.2 \%$ removal.

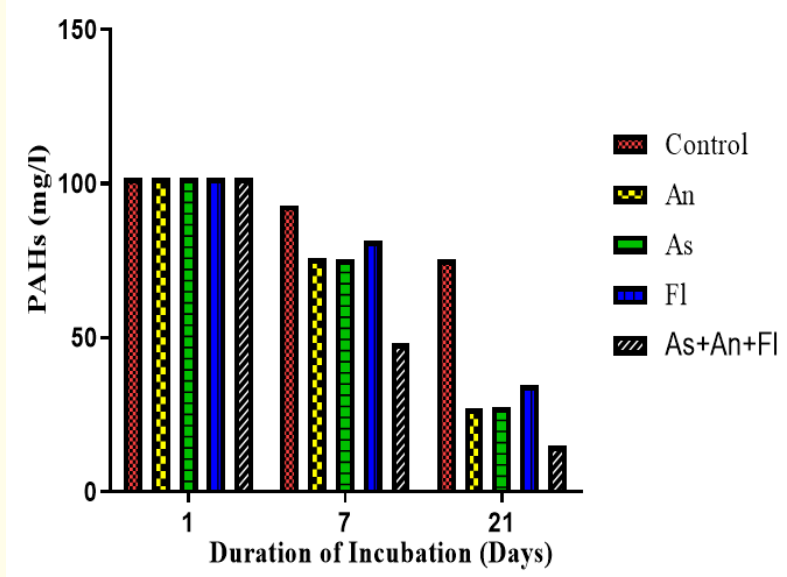

Figure 1: Biodegradation of PAHs by single and mixed culture (Aspergillus niger, Aspergillus sydowii, and Fusarium lichenicola).

The GC profile showing the degradation of polycyclic aromatic hydrocarbons (PAHs) by the control on day 1 and 21 are shown in figure 2 and 3 respectively. The polycyclic aromatic hydrocarbon on day 1 was $101.72992 \mathrm{mg} / \mathrm{l}$ with the following individual PAHs present; Naphthalene, Acenaphthylene, Acenaphthene, Anthracene and Chrysene. On day 21 the control recorded $75.40663 \mathrm{mg} / \mathrm{l}$ with no removal of the individual PAHs.

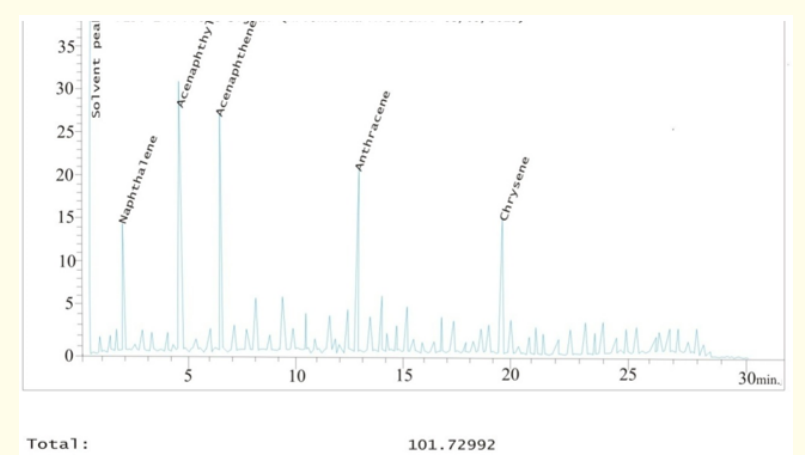

Figure 2: GC profile of the polycyclic aromatic hydrocarbons (PAHs) in control oilfield wastewater on day 1.

The GC profiles of individual fungus on day 21 are shown in figure 4-6. At day 21, there was complete removal of Naphthalene and Chrysene in Aspergillus niger treatment option. Aspergillus sydowii treatment option showed complete removal of Chrysene. There was incomplete removal of the individual PAHs in Fusarium lichenicola treatment options.

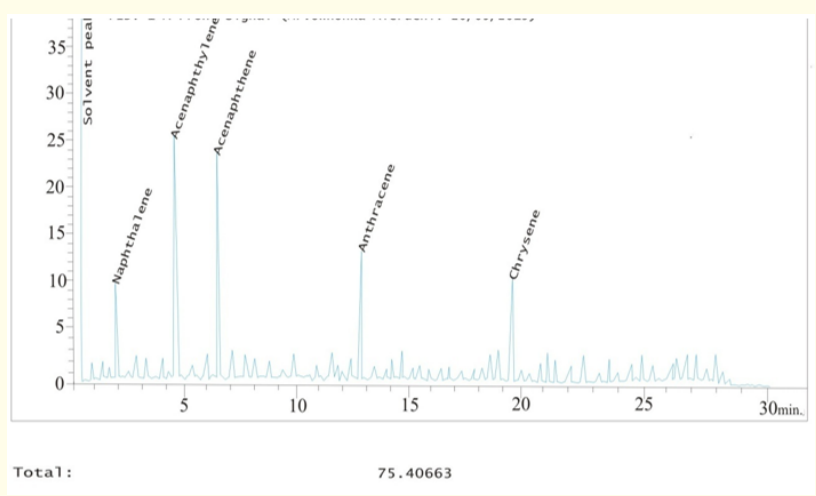

Figure 3: GC profile of the biodegradation of polycyclic aromatic hydrocarbons (PAHs) in the control oilfield wastewater on day 21.
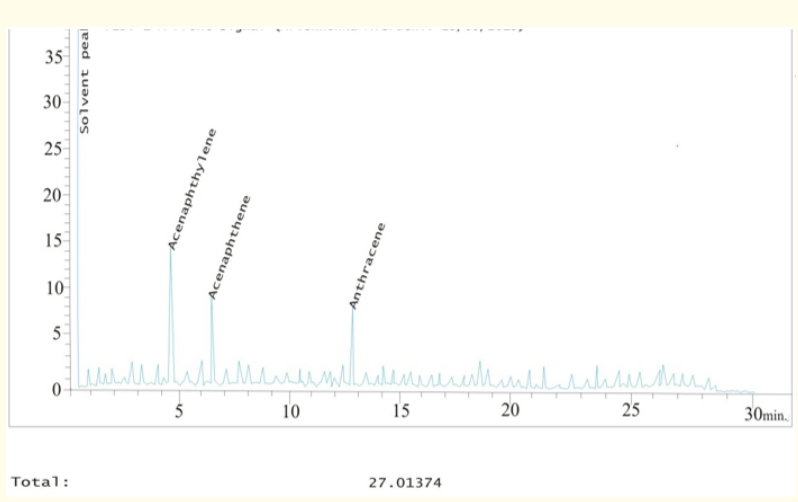

Figure 4: GC profile of the biodegradation of PAHs by Aspergillus niger on day 21.

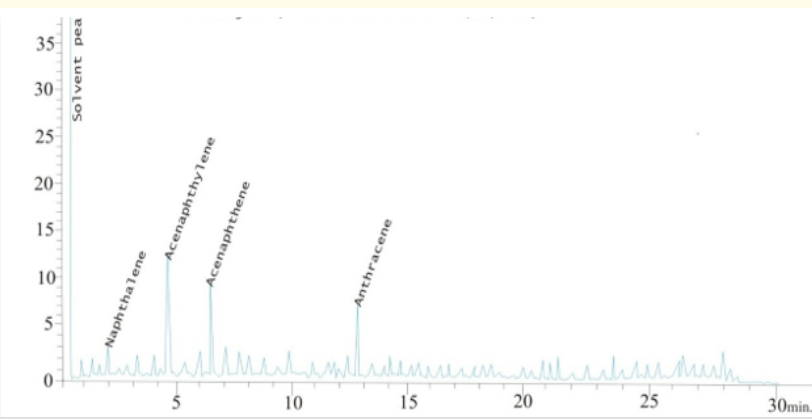

Total: $\quad 27.38876$

Figure 5: GC profile of the biodegradation of PAHs by Aspergillus sydowii on day 21.

The GC profile of mixed fungi on day 21 is shown in figure 7 . Naphthalene and Chrysene were completely removed on day 21 . There was reduction in the amount of individual PAHs remaining. 


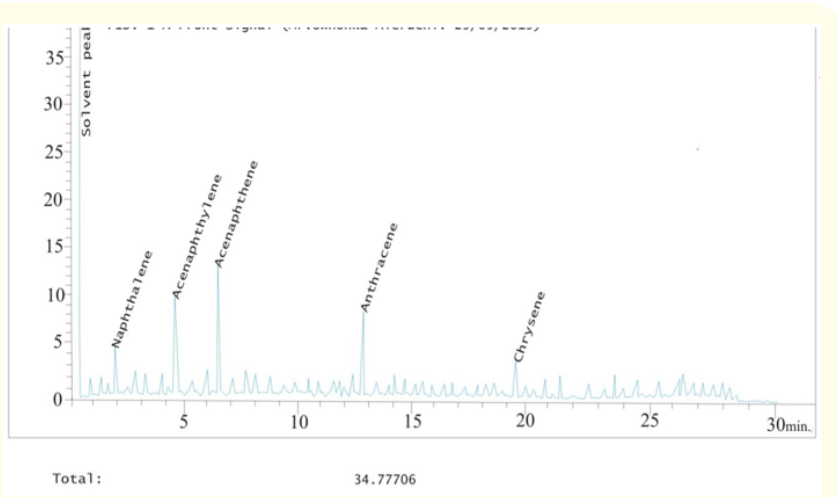

Figure 6: GC profile of the biodegradation of PAHs by Fusarium lichenicola on day 21.

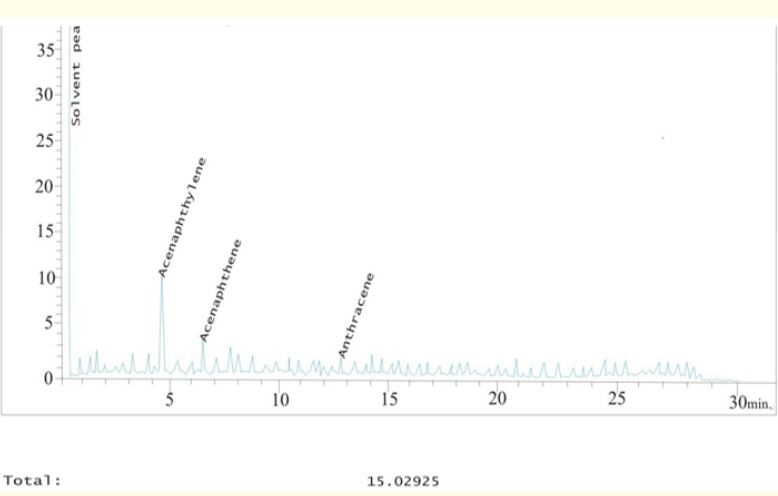

Figure 7: GC profile of the biodegradation of PAHs by Aspergillus niger + Aspergillus sydowii + Fusarium lichenicola on day 21 .

\section{Discussion}

Fungal potential to biodegrade polycyclic aromatic hydrocarbon was the focus of this research. The fungi used in the biodegradation study were molecularly identified as Aspergillus niger, Fusarium lichenicola and Aspergillus sydowii and were submitted to GenBank with accession numbers MN094359, MN094360 and MN094361 respectively. The PAHs on day 1 showed the same value in the treatment options and in the control. On day 7 , the treatment options including the control recorded reduction in the concentration of PAHs. Aspergillus sydowii recorded the highest removal of PAHs among the single fungus on day 7 which was followed by Aspergillus niger then Fusarium lichenicola which recorded the least removal. The mixed culture recorded high reduction on day 7. On day 21, the mixed culture recorded the highest percentage removal which was followed by the treatment options in the order of descending; Aspergillus niger, Aspergillus sydowii and Fusarium lichenicola. The lowest percentage removal was recorded in the control. There was a significant difference between the treatments options and the control on day 7 and 21 at $\mathrm{P} \leq 0.05$. The results showed the individual degradability of the fungus and how it enhanced their performance in the mixed culture. The results further suggested that the fungi used in the experiment showed mutual- istic and synergistic activities. The fungi in this study, Aspergillus niger, Aspergillus sydowii, and Fusarium lichenicola, has been reported for their biodegradation abilities by previous researchers [12-14]. Fungi possess decomposing abilities and several researchers [15-17] have reported that the fungal species isolated in this work were involved in the degradation of petroleum hydrocarbons. Fungi grow into large spectrum of substrates and they produce extracellular enzymes that can break through contaminants and remove the petroleum hydrocarbons [18]. Result of this work also supported the findings by other researchers [19-21] that mixed culture is a more effective seeders for biodegradation of PAHs. In a mixed culture, some species utilize intermediates of degradation of the original hydrocarbon produced by other members of the culture leading to complete degradation of the oil (Edna., et al. 2016). The reduction of PAHs recorded in the control could be attributed to natural attenuation as the oilfield wastewater also contains indigenous microorganisms but the process was generally slow.

On day 21, there was no clearance of individual PAHs in the control. Aspergillus niger showed total removal of Naphthalene and Chrysene. Aspergillus sydowii showed removal of Chrysene only while Fusarium lichenicola showed incomplete removal of individual PAHs on day 21.

The gas chromatography analysis on PAHs degradation on the treatment option containing the mixed culture showed complete clearance of Naphthalene and Chrysene on day 21. This can be attributed to combined biodegradation potentials possessed by $A s$ pergillus niger and Aspergillus sydowii. The chromatogram reported showed the difference in retention time and peak height between the control and the treatment options during the incubation periods, there were high reductions in the peaks of the treatment options.

\section{Conclusion}

In conclusion, the result of this research showed that the fungi isolated from soils of the oil production vicinity can be effectively utilized in bioaugmentation for the removal of hydrocarbon pollutants from contaminated environments.

\section{Bibliography}

1. Rahman KS., et al. "Enhanced bioremediation of n-alkane in petroleum sludge using bacterial consortium amended with rhamnolipid and micronutrients". Bioresources Technology 90 (2003): 159-168.

2. Mueller JG., et al. "Effect of inoculation on the biodegradation of weathered prudhoe Bay crude oil”. Journal of Industrial Microbiology 10 (1992): 95-102.

3. Hallier-Soulier S., et al. "Detection and quantification of degradative genes in soils contaminated by toluene". FEMS Microbiology 20 (1999): 121-133. 
4. Martello A. "Biodegradation: Cleaning up with Biology and Technology" 5 (1991): 7.

5. Aleruchi $\mathrm{O}$ and Obire 0 . "Quality characteristics of an oilfield produced water and its recipient discharge pond". E-Journal of Science and Technology 13.4 (2018): 1-10.

6. Obire 0 and Okudo I. "Effects of crude oil on a freshwater stream in Nigeria”. Discovery and Innovation 9 (1997): 25-32.

7. Wemedo SA. "Bioremediation potential of oilfield produced water in a crude oil contaminated soil in Nigeria". International Journal of Geography and Environmental Management 2.2 (2016): 49-57.

8. Williams JO and Aleruchi O. "Biodegradation potentials of Aspergillus sydowii and Fusarium lichenicola on total petroleum hydrocarbon in an oilfield wastewater in Rivers State". Journal of Advances in Microbiology 19.3 (2019): 1-7.

9. Saitou N and Nei M. "The neighbor-joining method: A new method for reconstructing phylogenetic trees". Molecular Biology and Evolution 4 (1987): 406-425.

10. Felsenstein J. “Confidence limits on phylogenies: An approach using the bootstrap". Evolution 39 (1985): 783-791.

11. Jukes TH and Cantor CR. "Evolution of protein molecules". In Munro HN, editor, Mammalian Protein Metabolism (1969): 21-132.

12. Birolli WG., et al. "Biodegradation of anthracene and several PAHs by the marine derived fungus Cladosporium sp CBMAI 1237". Maritime Pollution Bulletin 129.2 (2018): 525-533.

13. Davis JB and Westlake DWS. "Crude Oil Utilization by Fungi”. Canadian Journal of Microbiology, 25 (1979): 146-156.

14. Obire 0. "Studies on the biodegradation potentials of some microorganisms isolated from water systems of two petroleum producing areas in Nigeria". Nigerian Journal of Botany 1 (1988): 81-90.

15. Chaillan F., et al. "Identification and biodegradation potential of tropical aerobic hydrocarbon- degrading microorganisms". Research in Microbiology 155.7 (2004): 587-595.

16. Singh H. "Mycoremediation: Fungal Bioremediation". New York: Wiley Inter science (2006): 592.

17. Bik HM., et al. "Dramatic shifts in benthic microbial eukaryote communities following the deep water horizon oil spill". PloS One (2012).
18. Balaji V and Ebenezer P. "Optimization of extracellular lipase production in Colletotrichum gloeosporioides by solid state fermentation". Indian Journal of Science and Technology 1 (2008):1-8.

19. Obire $O$ and Anyanwu EC. "Impact of various concentrations of crude oil on fungal populations of soil". International Journal of Environmental Science and Technology 6 (2009): 211-218.

20. Bento FM and Gaylarde CC. "Biodeterioration of stored diesel oil: Studies in Brazil". International Biodeterioration and Biodegradation 47 (2001): 107-112.

21. Facundo JMR., et al. "Biodegradation of diesel oil in soil by a microbial consortium". Water, Air and Pollution 128 (2001): 313-320.

\section{Assets from publication with us}

- Prompt Acknowledgement after receiving the article

- Thorough Double blinded peer review

- Rapid Publication

- Issue of Publication Certificate

- High visibility of your Published work

Website: https://www.actascientific.com/

Submit Article: https://www.actascientific.com/submission.php Email us: editor@actascientific.com

Contact us: +919182824667 